\title{
硫酸酸性溶液中における塩素酸イオンと 過酸化水素の反応
}

(1977 年 3 月 25 日受理)

山崎澄男*。大浦 博樹*・住吉正史*・津留寿昭*・中森一誠**

硫酸水溶液中での塩索酸ナトリウムと過酸化水素の反応生成物は二酸化塩素, 酸 素 それ飞塩素であ

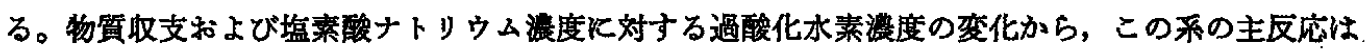

$$
2 \mathrm{ClO}_{8}-\mathrm{H}_{8} \mathrm{O}_{2}+2 \mathrm{H}^{+} \longrightarrow 2 \mathrm{ClO}_{2}+\mathrm{O}_{2}+2 \mathrm{H}_{2} \mathrm{O}
$$

で表わされる。ここで塩素の生成過程は（1）式で生成した二酸化塩素が過酸化水秦の存在のもとに，塩 化物イオンと塩菜酸イオンに不均化し，その塩化物イオンが存在する塩素酸イオンと酸性溶液中で二次 的淿応し塩素を生成するものと推定される。

(1)式の反応機構は，二酸化塩素の生成速度が塩素酸イオンおよび過酸化水素に関してそれぞれ 1 次 であること，また Haber-Weiss，Baxendale おょび Stein らの過酸化水素による金属イオンの酸化お

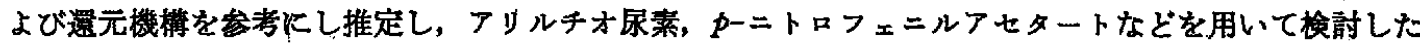
ところ、つぎの上う筷考えることができる。

$$
\begin{aligned}
& \mathrm{H}_{2} \mathrm{O}_{2}+\mathrm{H}^{+}=\mathrm{H}_{8} \mathrm{O}_{2}^{+}\left(p \mathrm{~K}_{a}=-4.7\right) \\
& \mathrm{ClO}_{3}{ }^{-}+\mathrm{H}_{8} \mathrm{O}_{2}+\underset{h_{-1}}{\stackrel{h_{1}}{\rightleftarrows}} \mathrm{ClO}_{2}+\mathrm{H}_{2} \mathrm{O}+\mathrm{HO}_{2} \text {. } \\
& \mathrm{HO}_{2} \cdot+\mathrm{ClO}_{8}^{-}+\mathrm{H}^{+} \stackrel{k_{2}}{\longrightarrow} \mathrm{ClO}_{2}+\mathrm{O}_{2}+\mathrm{H}_{2} \mathrm{O}
\end{aligned}
$$

過酸化水素の自己分解恃（3）および(4)の反応汇くらべると無視できた。

ここで $k_{2} \gg k_{-1}$ で，硫酸濃度が一定ならば二酸化塩素およひ酸素の生成速度は 2 次反応で表わされ， この見かけの速度定数 $k_{1}$ は，たとえば $30^{\circ} \mathrm{C}$ に和いて $6 \mathrm{~mol} / l$ 硫酸溶液で $1.85 l / \mathrm{mol} \cdot \mathrm{min}, 7 \mathrm{~mol} / l$ 硫 酸溶浓で $13.62 \mathrm{l} / \mathrm{mol} \cdot \mathrm{min}$ であることがわかった。

\section{1 粕 零}

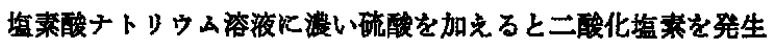
するが，この系過酸化承素を添加すると，より低い漫度の硫酸 で二酸化程素が容易に発生することは㷩味深い。るとると過酸化 水萃俚亚塩菜酸ナトシウムによる酸性漂白のさい発生する二酸

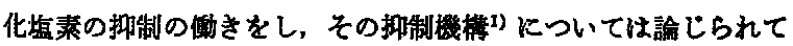
いるが，硫酸溶液中における塩絜酸イオンと過酸化水策から二酸 化垍素を得る反応については特許")の一つに報告されているにす ぎない。

著者らはこの反応について物質取支の面およさひ速度諭的考察を 行ない二三の知見を得たので報告する。

\section{2 实涘}

2.1 試 乘

試薬はすへて市眅特級品を使用した。塩素酸ナトリウムはとく

* 九州库業大学工学部工業化学教室, 813 福詷市東区松香台

** 佐賀大学理工学部工業化学教室, 840 佐贺市本庄町

1）石 源三，工化, 65, 470(1962).

2) U.S.P., 2, 358, 866(1944).
K㙁化物イオン，亜㙁軎酸イオンなどを含まないことを確かめ た。

過酸化水素硫酸溶液（約 $0.75 \mathrm{~mol} / l$ ) はそのつど調製し，力価 を定めた。

\section{2 装置およひ実歌操作}

既報9で示した実験装置で行なった。操作は $30 \pm 1{ }^{\circ} \mathrm{C}$ の佰温槽

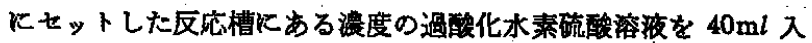
れ，空素ガスを流しながら，これКある淡度の塩䒧酸ナトリウム 溶液を $10 \mathrm{ml}$ 加え，生成する二酸化㙁菜，酸桲および㙁素などの ガスをヨウ化カリウムの中性溶液 (Hasting-Sendory の緩衝液 で $\mathrm{pH} \fallingdotseq 7.5$ に調整）へ導入し，分析することにより反応前後の 溶夜の組成および発生ガス量を測定した。

分析方法：発生ガス量で二酸化塩莱および筥素の混合物は常

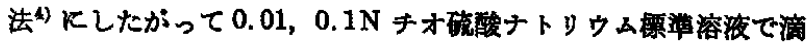
定し，算出した。反応後の溶液の組成で塩化物イオンは硝酸銀を 用いた電流滴定，㙁素酸イオンは西酼酸水溶液で㙁化物イオンに 還元して硝酸銀を用いた電流滴定，過酸化本来は過マンガン酸塩

3）山㱦澄男, 大浦博樹, 中森一誠, 日化, 1975, 1315.

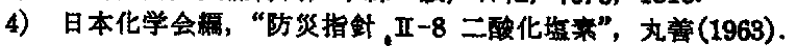


Table 1 Material balance for chlorine element and quantitative change of any other species in $6 \mathrm{~mol} / l \mathrm{H}_{2} \mathrm{SO}_{4}$

\begin{tabular}{|c|c|c|c|c|c|c|}
\hline & Exp. No. & 1 & 2 & 3 & 4 & 5 \\
\hline \multirow{3}{*}{$\begin{array}{l}\text { Reaction } \\
\text { system } \\
\text { (1) }\end{array}$} & $\mathrm{H}_{2} \mathrm{O}_{2} / \mathrm{ClO}_{3}-$ & 0.25 & 0.65 & 1 & 5 & 10 \\
\hline & $\mathrm{NaClO}_{\mathrm{s}}(\mathrm{mol} / \mathrm{l})$ & 0.0598 & 0.0598 & 0.0598 & 0.0598 & 0.0598 \\
\hline & $\mathrm{H}_{2} \mathrm{O}_{2}(\mathrm{moll})$ & 0.0138 & 0.0393 & 0.0626 & 0.3210 & 0.6616 \\
\hline \multicolumn{2}{|c|}{ Reaction time (min) } & 20 & 20 & 10 & 4 & 3 \\
\hline \multirow{4}{*}{$\begin{array}{l}\text { Product } \\
\text { system } \\
\text { (2) }\end{array}$} & $\mathrm{NaClO}_{\mathrm{a}}(\mathrm{mol} / \mathrm{l})$ & 0.0360 & 0.0134 & 0.0142 & 0.0139 & 0.0167 \\
\hline & $\mathrm{H}_{2} \mathrm{O}_{2}(\mathrm{~mol} / \mathrm{l})$ & 0.0026 & 0.0173 & 0.0389 & 0.2908 & 0.6215 \\
\hline & $\mathrm{ClO}_{2}(\mathrm{~mol} / \mathrm{l})$ & 0.0220 & 0.0425 & 0.0415 & 0.0395 & 0.0375 \\
\hline & $\mathrm{Cl}_{2}(\mathrm{~mol} / \mathrm{l})$ & 0.0002 & 0.0009 & 0.0011 & 0.0014 & 0.0015 \\
\hline $\begin{array}{l}\text { (2) }-(1) \\
\text { for } \mathrm{ClO}_{3}- \\
\text { and } \mathrm{H}_{2} \mathrm{O}_{2}\end{array}$ & $\begin{array}{l}\Delta \mathrm{ClO}_{\mathrm{s}}^{-}(\mathrm{mol} / \mathrm{l}) \\
\Delta \mathrm{H}_{2} \mathrm{O}_{2}(\mathrm{~mol} / \mathrm{l})\end{array}$ & $\begin{array}{l}0.0238 \\
0.0112\end{array}$ & $\begin{array}{l}0.0464 \\
0.0220\end{array}$ & $\begin{array}{l}0.0456 \\
0.0239\end{array}$ & $\begin{array}{l}0.0459 \\
0.0302\end{array}$ & $\begin{array}{l}0.0431 \\
0.0401\end{array}$ \\
\hline \multirow{5}{*}{$\begin{array}{l}\text { Stoichio- } \\
\text { metry }\end{array}$} & $\Delta \mathrm{ClO}_{3}-/ \Delta \mathrm{H}_{2} \mathrm{O}_{2}$ & 2.1 & 2.1 & 1.9 & 1.5 & 1.1 \\
\hline & $\mathrm{ClO}_{2} / \Delta \mathrm{H}_{2} \mathrm{O}_{2}$ & 2.0 & 1.9 & 1.7 & 1.3 & 0.9 \\
\hline & $\mathrm{ClO}_{2}+2 \mathrm{Cl}_{2} / \Delta \mathrm{H}_{2} \mathrm{O}_{2}$ & 2,0 & 2.0 & 1.8 & 1.4 & 1.0 \\
\hline & mposition (\%) & $45^{1}$ & 77 & 76 & 76 & 72 \\
\hline & $(\%)^{\alpha}$ & 5.9 & 4.5 & 4.2 & 7.8 & 6.0 \\
\hline
\end{tabular}

a) Error $(\%)=\left[\left\{\Delta \mathrm{ClO}_{3}{ }^{-}-\left(\mathrm{ClO}_{2}+2 \mathrm{Cl}_{2}\right)\right\} / \Delta \mathrm{ClO}_{3}{ }^{-}\right] \times 100$

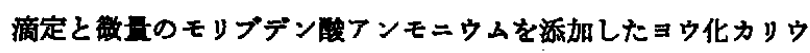
ム溶液を用いたチオ硫酸塩滴定とを併用した。

なお，二酸化塩来の発生の速度論的な考察仕 Beckman 分光光 度計 DB-G を用い，10 mm 石英フ夕付をルを使用して，波長 $360 \mathrm{~nm}$ て吸光度の堌加異を測定することにより二酸化塩素の生 成量を求め，そして(1)式の関保住ついて基媪酸イオンの減少 量を拥べることにより行なった。

また，中間生成物として考えられる $\mathrm{HO}_{2}$ ・の存在を碓かめるた めにつぎのよらな実験を行なった。まず反応樯（した光銀紙で包 んた $100 \mathrm{ml}$ の三角フラスコ）K50〜70 ml の反応溶液を入れ,

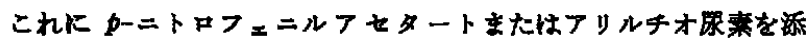
加し， マグネテックスターラーでかきまぜ, 生成したガス（酸菜 と二酸化塩素) をョウ化カリウム中性溶液中に逆さま垂直に立 てた通常の $50 \mathrm{ml}$ ビニレット（この中にすヨウ化カリウム中性 溶液が入っている）下導入しヨウ化カリウムと反它しない気体を 酸素としてその体稹（压力補正）の增加によって酸素の発生量を 測定し検討した。

\section{3 实 殹結果}

\section{1 剒莱についての物艋取支}

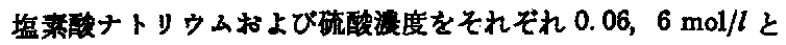
一定にし，過酸化水来を塩桲酸ナトリウムの 0.25〜10 倍モル港 度と亲化させた条件下での反応前後における溶液組成たよび発生 ガスの種類および量をみたのが表 1 である。

この反応で最終生成物として忙二酸化㙁妻, 酸素および塭莱で あると見なすことができる。また同一硫酸渡度では過酸化水素漫 度が高くなるにしたがって二酸化塩莱の発生速度が大きくなって

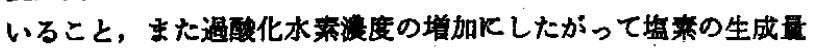
は微小ながら大きくなっている，たとえば反応初期塩萧酸イオン 缶度火対子る反応初期過酸化水菜瀑度の比 $\left[\mathrm{H}_{2} \mathrm{O}_{2}\right]_{0} /\left[\mathrm{ClO}_{3}{ }^{-}\right]_{0}$ （以下初期渡度比をこのように畵くことにする）が 0.25 で発生 する塩素量は同時に発生する二酸化塩菜量との含量（全塩素系为 ス量）に対して 2mol\% であったるのが 10.0 では $4 \mathrm{~mol} \%$ K增 加していることがかかる。

$\left[\mathrm{H}_{2} \mathrm{O}_{2}\right]_{0} /\left[\mathrm{ClO}_{8}-\right]_{0}$ が 1 より小さい実検条件においては $\Delta \mathrm{ClO}_{3}{ }^{-}$

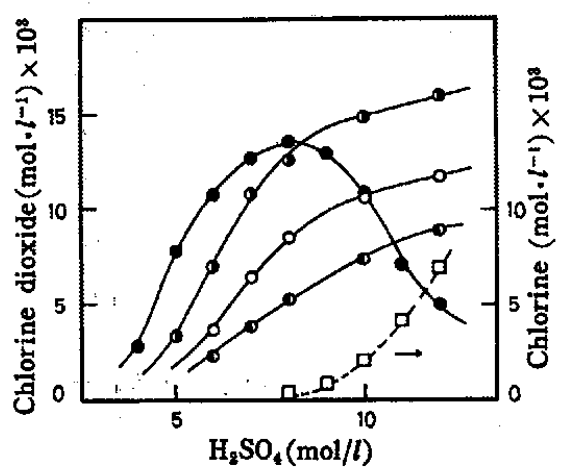

Fig. 1 Effect of sulfuric acid on the formation of chlorine dioxide and chlorine

Temperature : $30^{\circ} \mathrm{C}$, Reaction time : $10 \mathrm{~min}, 0.02$ $\mathrm{mol} / \mathrm{l} \mathrm{NaClO}_{3}$

$\mathrm{H}_{2} \mathrm{O}_{2} / \mathrm{NaClO}_{\mathrm{a}}$

$$
D: 0.25, \bigcirc: 0.5, O: 1, \bigcirc: 5\left(\square: \mathrm{Cl}_{2}\right)
$$

$/ \Delta \mathrm{H}_{2} \mathrm{O}_{2} \doteqdot 2$ また $\mathrm{ClO}_{2} / \Delta \mathrm{H}_{2} \mathrm{O}_{2} \fallingdotseq 2$ であり, 㙁你ガス量恃他の生成 物に対して小さいのでこれを無視したらえで charge balance を 考光ると，この条件下では，つぎの反応式が支配的であるとい充 る。

$$
2 \mathrm{ClO}_{3}^{-}+\mathrm{H}_{2} \mathrm{O}_{2}+2 \mathrm{H}^{+} \longrightarrow 2 \mathrm{ClO}_{2}+\mathrm{O}_{2}+2 \mathrm{H}_{2} \mathrm{O}
$$

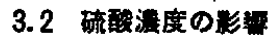

図 1 は $0.02 \mathrm{~mol} / l$ 塩素酸ナトリウム溶液に対し過酸化水秦を 0.25〜5.0 倍モル量変化させた四つの試料について硫酸灌度を 4 $\sim 12 \mathrm{~mol} / l$ まで変化させた场合，反応時間 10 分間に生成した二 酸化塩素および塩素の漫度を示したるのである。

$\left[\mathrm{H}_{2} \mathrm{O}_{2}\right]_{0} /\left[\mathrm{ClO}_{8}-\right]_{0}<1$ では, 過酸化水絜浪度が增加すればする 注ど二酸化塩素の生成量は增加する。かつ，また硫酸灌度が增加

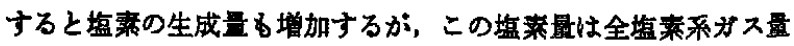
の数モルパーセント以下である。一方, $\left[\mathrm{H}_{2} \mathrm{O}_{2}\right]_{0} /\left[\mathrm{ClO}_{3}{ }^{-}\right]_{0}>5$ で は, 硫酸浱度 $8 \mathrm{~mol} / l$ 以上では二酸化塩素の生成量は激娍し，そ のかわりに塩事が多量（約 $12 \mathrm{~mol} \%$ ) 飞生成するといった現象が 見られる。 


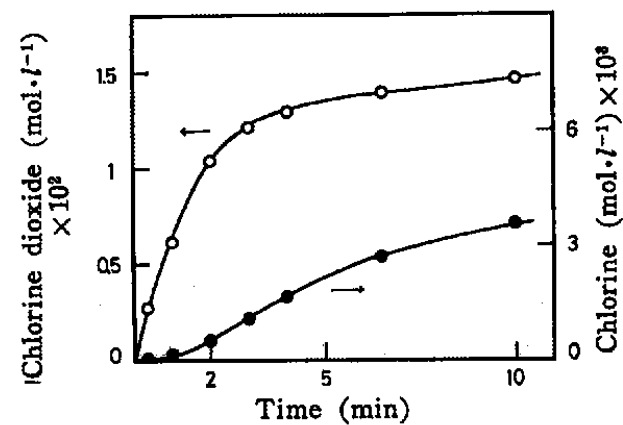

Fig.2 Formation of chlorine dioxide and chlorine as the function of reaction time

Temperature : $30^{\circ} \mathrm{C}, 0.02 \mathrm{~mol} / / \mathrm{NaClO}_{3}, 0.8 \mathrm{~mol} / \mathrm{l}$ $\mathrm{H}_{2} \mathrm{O}_{2}, 9 \mathrm{~mol} / l \mathrm{H}_{2} \mathrm{SO}_{4}$

$\mathrm{O}: \mathrm{ClO}_{2}, \mathrm{O}: \mathrm{Cl}_{2}$

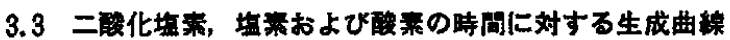
$0.02 \mathrm{~mol} / \mathrm{l}$ 塩菜酸ナトリウムとその 40 倍瀑度である $0.8 \mathrm{~mol} / \mathrm{l}$

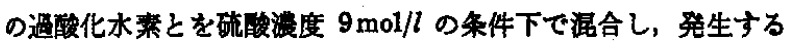

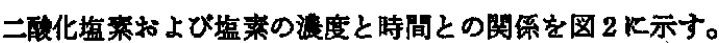

二酸化塩素の生成は通常の曲線を示すが，塩素の生成は時間に 対してS字形を示している。このことは二酸化塩素が過酸化水菜 で僄元されて塩化物イオンになり, ‘ざに二次的な反応としてた の塩化物イオンが牫りの塩尞酸テトリウムと硫酸水溶液で反応し て塩素を生成するといら過程をとると推定される。なお過酸化水 菜存在下での二酸化塩类は不均化反応として塩化物イオンと塩素 酸イオンになることが知られている。

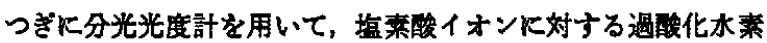

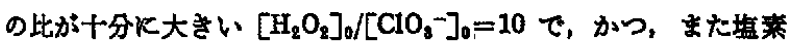
の生成が無視される $7 \mathrm{~mol} / l$ 硫酸浱度溶液で波長 $360 \mathrm{~nm}$ のビー クの時間的变化から二䣼化塭素の時間的生成量を求め, つ民゙にこ の量から(1)式に基ついて塩素酸イオン渡を算出し，その対数

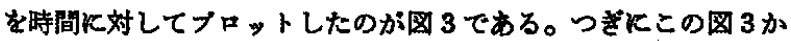
ら求めた $k_{\text {obe }}$ を過酸化水来化ついてブロットしたのが四 4 であ る。これらの図からこの(1)式の反応恃塩素酸イオンおよび過酸 化水美に対してそれぞれ1次であることがわかった。また反応速

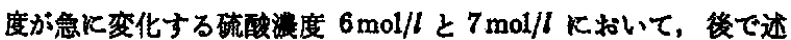
ベ(5)式で表わされる見かけの 2 次速度定数 $k_{1}\left(30^{\circ} \mathrm{C}\right)$ はそれ

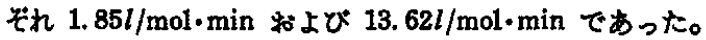

さらK HO $\mathrm{H}_{2}$ ・の存在を確かめるためにつくった实験装直を用い $\tau 0.1 \mathrm{~mol} / l$ 㙁索酸ナトリウムと過酸化水素 $4 \times 10^{-8}, 6 \times 10^{-8}$, $8 \times 10^{-8}$ それに $1 \times 10^{-2} \mathrm{~mol} / l$ の $6 \mathrm{~mol} / l$ 硫酸溶液を反応させて 発生した酸素の初速度を過酸化水索初瀑度に対してナ゙ッットした のが図 5 である。この図から酸素の発生速度恃過酸化水素に対し て1次であると推定できる。

\section{4 考㖨およひ結猃}

以上の実匰結果から，硫酸水溶液中の塩案酸イオンと過酸化水

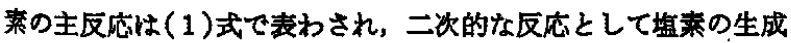
が考えられることがわかった。また（1)式が支配的である領城で の㙁素酸イオンの減少速度は塩妻酸イオンォよび過酸化水素に関 してそれぞれ1次であることなどから，酳酸溶液中での塩素酸イ

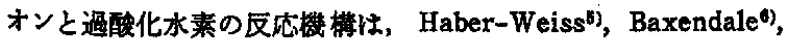

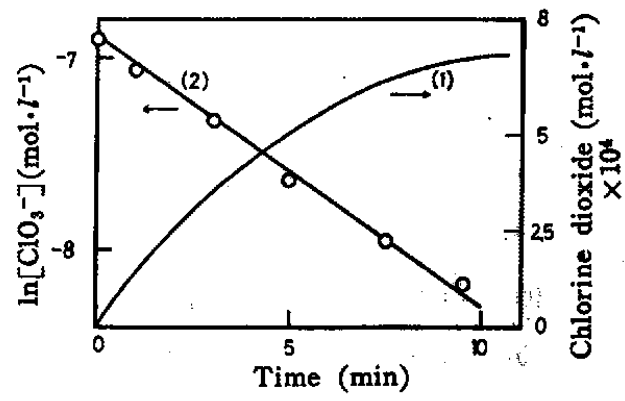

Fig. 3 Relation of formation of chlorine dioxide with time ( 1 ) and that of chlorate concentration, calculated from equation (1), with time (2) (left hand-side) at $30^{\circ} \mathrm{C}$

$0.001 \mathrm{~mol} / l \mathrm{NaClO} \mathrm{O}_{3}, 0.01 \mathrm{~mol} / l \mathrm{H}_{2} \mathrm{O}_{2}, 7 \mathrm{~mol} / l \mathrm{H} \mathrm{H}_{2} \mathrm{SO}_{4}$

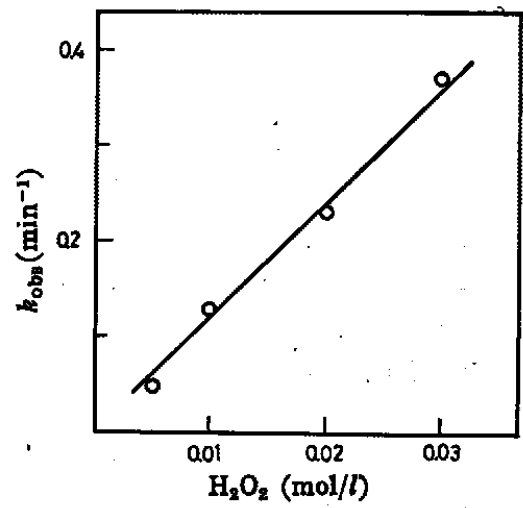

Fig. 4 Relation between $\boldsymbol{k}_{\mathrm{obs}}$ and hydrogen peroxide concentration

Temperature : $30^{\circ} \mathrm{C}, 0.001 \mathrm{~mol} / l \mathrm{NaClO}_{3}, 7 \mathrm{~mol} / \mathrm{l}$ $\mathrm{H}_{2} \mathrm{SO}_{4}$

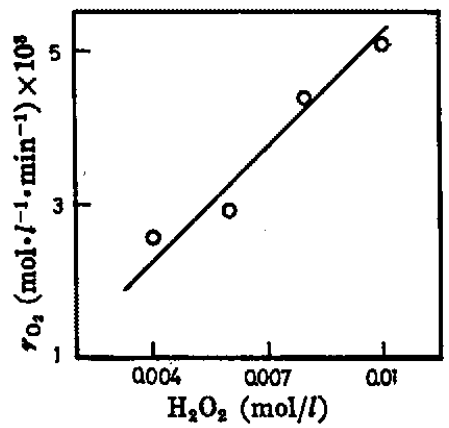

Fig. 5 Relation between the rate of evolution of oxygen and hydrogen peroxide concentration

Temperature : $30^{\circ} \mathrm{C}, 0.1 \mathrm{~mol} / l \mathrm{NaClO}_{3}, 6 \mathrm{~mol} / l \mathrm{H}_{2} \mathrm{SO}_{4}$

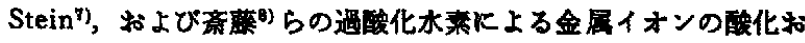
よび瞇元機構を参考にして、っぎのよらに拷ることができる。

5) F. Haber, J. Weiss, Proc. Roy. Soc. London, A 147, 332(1934); Chem. Rev., 50, 375(1952).

6) J. H. Baxendal, H. R. Hardy, Trans. Faraday Soc., 47, 963(1951).

7) S. Baer, G. Stein, J. Chem. Soc., 1953, 3176.

8) E. Saito, B. H. J. Bielski, J. Am. Chem. Soc., 83, 4467 (1961). 


$$
\begin{aligned}
& \mathrm{H}_{2} \mathrm{O}_{2}+\mathrm{H}^{+}=\mathrm{H}_{8} \mathrm{O}_{2}^{+}\left(p K_{4}=-4.7\right)^{9)} \\
& \mathrm{ClO}_{8}^{-}+\mathrm{H}_{8} \mathrm{O}_{2}+\underset{k_{1}}{\stackrel{k_{1}}{\longrightarrow}} \mathrm{ClO}_{2}+\mathrm{H}_{2} \mathrm{O}+\mathrm{HO}_{2} . \\
& \mathrm{HO}_{2} \cdot+\mathrm{ClO}_{3}^{-}+\mathrm{H}^{+} \stackrel{k_{2}}{\longrightarrow} \mathrm{ClO}_{2}+\mathrm{O}_{2}+\mathrm{H}_{2} \mathrm{O}
\end{aligned}
$$

途中にごく酓の過酸化水菜の自己分解

$$
\left(\begin{array}{l}
\mathrm{HO}_{2} \cdot+\mathrm{H}_{2} \mathrm{O}_{2} \longrightarrow \mathrm{O}_{2}+\mathrm{H}_{2} \mathrm{O}+\mathrm{HO} \cdot \\
\mathrm{HO} \cdot+\mathrm{H}_{2} \mathrm{O}_{2} \longrightarrow \mathrm{H}_{2} \mathrm{O}+\mathrm{HO}_{2}
\end{array}\right.
$$

があるとみられるが(3)扎よび(4)式化くらべると無視され得 る。したがって, すし $k_{2} \gg k_{-1}$ で，硫酸濃度が一定ならば

$$
\begin{aligned}
& -\mathrm{d}\left[\mathrm{ClO}_{3}-\right] / \mathrm{d} t=\mathrm{d}\left[\mathrm{ClO}_{2}\right] / \mathrm{d} t=\frac{2 k_{1} k_{2}\left[\mathrm{ClO}_{3}-\right]^{2}\left[\mathrm{H}_{2} \mathrm{O}_{2}\right]}{k_{-1}\left[\mathrm{ClO}_{2}\right]+k_{2}\left[\mathrm{ClO}_{3}-\right]} \\
& \quad \therefore 2 k_{1}\left[\mathrm{ClO}_{3}-\right] \cdot\left[\mathrm{H}_{2} \mathrm{O}_{2}\right] \\
& \mathrm{d}\left[\mathrm{O}_{2}\right] / \mathrm{d} t=k_{1}\left[\mathrm{ClO}_{8}-\right] \cdot\left[\mathrm{H}_{2} \mathrm{O}_{2}\right]
\end{aligned}
$$

である。この(5)および(6)式は図 3，4および5の実験結果と よく一致する。

ところが中䦓体である $\mathrm{HO}_{2} \cdot$ がフクリ ニトリル、フクリルフ ミト，醐酸どニルなどの高分子生成反応の触媒として作用するな ら塩素酸イオンの減少量飞奶する酸菜の生成量（過酸化本菜の自 己分解を補正した）の比 $\left(\mathrm{O}_{2} / \Delta \mathrm{ClO}_{\mathrm{a}}^{-}\right)$は 0.5 より小さいはずで あるが，しかしこれらの試薬を添加しても $\mathrm{O}_{2} / 4 \mathrm{ClO}_{3}$ 一性注 0.5 てあり，また高分子物筫の生成る諗められなかったことから， HO ・はこれら添加試薬と反応しないか, 反応してもその速度が (4)式より非常飞遇いことが推定される。しかし表 2 に示すよら K $p$-ニトロフェニルアセタート10) を添加した埸合, いくぶん多 量の酸素を生成したことは， $\mathrm{HO}_{2}$ ・のヨジカル1個が $p$ ートロフ

9) J.O.Edwards, "Inorganic Reaction Mechanism", W. A. Benjamin, New York (1965) p. 79.
Table 2 Effect of addition of p-nitrophenyl acetate and allylthiourea on evolution of oxygen in a solution of $0.05 \mathrm{~mol} / / \mathrm{NaClO} \mathrm{O}_{3}, 0.05 \mathrm{~mol} / \mathrm{l}$ $\mathrm{H}_{2} \mathrm{O}_{2}$ and $4.8 \mathrm{~mol} / l \mathrm{H}_{2} \mathrm{SO}_{4}$

\begin{tabular}{lc}
\multicolumn{1}{c}{ Added reagent } & $\mathrm{O}_{2} / \Delta \mathrm{ClO}_{3}{ }^{-\alpha)}$ \\
\hline None & 0.52 \\
Saturated $p$-nitrophenyl acetate & 0.59 \\
$7 \times 10^{-2} \mathrm{~mol} / l$ Allylthiourea & $\left.0.25^{b}\right)$
\end{tabular}

a) Average value of several experiments.

b) The chlorate and oxygen generated in the reaction of $0.05 \mathrm{~mol} / l \mathrm{NaClO}_{8}$ and $7 \times 10^{-2} \mathrm{~mol} / l$ allylthiourea in $4.8 \mathrm{~mol} / l \mathrm{H}_{2} \mathrm{SO}_{4}$ was subtracted.

ニニルアセタートと反応して $2 \mathrm{~mol}$ 以上の酸素を発生する反応 が比較的速い速度で起こっていることを示するのであろら。また $\mathrm{HO}_{2} \cdot$ を取り除く作用をるつ化合物 (scavenger) として報告さ

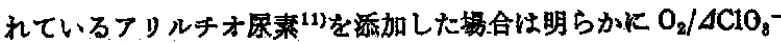
が0.5より小さいことがわかった。なお，それぞれの実跧におい て過酸化水素の䟽酸溶液にこれら試薬を添加して空实駼をした埸 合，過酸化水素の自己分解火上万微量の酸素の発生（この酸素县

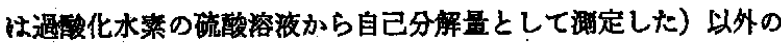
酸秦の発生はないことを確かめた。

以上のことから(1)式の反応は $\mathrm{HO}_{2}$.を中闃体として(3)式が 起こり，つぎに(4)式が起こるような逐次反就程をとるるのと 思われる。

（1976 年 10 月，日本化学会九州 - 中国四国支部合同大会（一 部) 讓演)

10) W.P. Jencks, J. Carriuolo, J. Am. Chem. Soc., 82, 1778(1960).

11) P. Alexander, M. Fox, Nature, 170, 1022(1952).

\title{
The Reaction of Chlorate with Hydrogen Peroxide in Sulfuric Acid Solution
}

\author{
Sumio Yamasaki*, Hiroki Ohura*, Masashi Sumryoshi*, \\ Sumiaki Tsuru* and Issei NAkamori** \\ * Department of Industrial Chemistry, Faculty of Engineering, \\ Kyushu Sangyo University ; Matsugadai, Higashi-ku, \\ Fukuoka-shi 813 Japan \\ ** Department of Industrial Chemistry, Faculty of Science and \\ Engineering Saga University ; Honjo-cho, \\ Saga-shi 840 Japan
}

By considering material balances and effects of concentration ratio of hydrogen peroxide to chlorate, it was found that products of the reaction between chlorate and hydrogen peroxide were chlorine dioxide, chlorine and oxygen, and that amounts of chlorine was small as compared with others.

The main reaction was represented by the equation (1),

$$
2 \mathrm{ClO}_{3}-+\mathrm{H}_{2} \mathrm{O}_{2}+2 \mathrm{H}^{+}=2 \mathrm{ClO}_{2}+2 \mathrm{H}_{2} \mathrm{O}+\mathrm{O}_{2}
$$

The formation of chlorine could be explained by assuming that chlorine dioxide first disproportionate to chloride in the hydrogen peroxide solution and this chloride reacted with chlorate in sulfuric acid solution.

The reaction rate was estimated to be first order for both $\mathrm{ClO}_{3}^{-}$and $\mathrm{H}_{2} \mathrm{O}_{2}$ by measuring the change in absorbance at $360 \mathrm{~nm}$.

The perhydroxyl radical $\mathrm{HO}_{2} \cdot$ was found to play an important role in this reaction by using 
$p$-nitrophenyl acetete and allylthiourea.

Based on the assumption of the oxidation and reduction mechanism of hydrogen peroxide with metal ion proposed in the previous reports by Haber, Weiss, Baxendale, Saito and Stein, following equations were proposed as elementary reactions.

$$
\begin{aligned}
& \mathrm{H}_{2} \mathrm{O}_{2}+\mathrm{H}^{+}=\mathrm{H}_{8} \mathrm{O}_{2}^{+} \quad\left(p \mathrm{~K}_{2}=-4.7\right) \\
& \mathrm{ClO}_{3}^{-}+\mathrm{H}_{3} \mathrm{O}_{2}^{+} \underset{k_{-1}}{\stackrel{k_{2}}{\rightleftharpoons}} \mathrm{ClO}_{2}+\mathrm{H}_{2} \mathrm{O}+\mathrm{HO}_{2} . \\
& \mathrm{HO}_{2}+\mathrm{ClO}_{3}^{-}+\mathrm{H}^{+} \stackrel{k_{2}}{\longrightarrow} \mathrm{ClO}_{2}+\mathrm{H}_{2} \mathrm{O}+\mathrm{O}_{2}
\end{aligned}
$$

Experimental results favored the appropriateness of these derived equations. 